\title{
A rare cause of secondary hemophagocytic lymphohistiocytosis: systemic loxoscelism
}

\author{
Tuğba Erat ${ }^{1 \oplus}$, Aysun Yahşi $^{1 \oplus}$, Cem Çanakç1 $^{2 \odot}{ }^{\circ}$ Aybike Korkmaz $^{2 \odot}$, \\ Ceyda Karahan ${ }^{2 \odot}$, Talia İleri ${ }^{3 \odot}$, Savaş Serel ${ }^{4 \odot}$, Huban Atilla ${ }^{5 \odot}$, Nihal Kundakç1 ${ }^{6 \odot}$, \\ Halil Özdemir ${ }^{1 \oplus}$, Erdal İnce ${ }^{1 \oplus}$, Ergin Çiftçi ${ }^{1 \oplus}$ \\ Divisions of ${ }^{1}$ Pediatric Infectious Diseases, ${ }^{3}$ Pediatric Hematology and Oncology, ${ }^{2}$ Department of Pediatrcis, Departments of ${ }^{4}$ Plastic \\ Reconstructive and Aesthetic Surgery, ${ }^{5}$ Ophthalmology and ${ }^{6}$ Dermatology, Ankara University Faculty of Medicine, Ankara, Turkey.
}

\begin{abstract}
Background. Loxoscelism is caused by the bite of a specific spider type called the Loxosceles genus. In Turkey, most cases are seen after L. rufescens bites. Clinical manifestation of the bites ranges from local cutaneous reaction to severe ulcerative necrosis. Systemic loxoscelism may also occur.

Case. Herein, we report a previously healthy five-year-old male patient who developed a secondary hemophagocytic lymphohistiocytosis after a presumed brown spider bite. He was treated with dexamethasone. Within the following 14 days, hemophagocytic syndrome resolved. Local hyperbaric oxygen therapy was applied to the necrotic areas.
\end{abstract}

Conclusion. Secondary hemophagocytic lymphohistiocytosis may develop after systemic loxoscelism. In the presence of persistent fever, hepatosplenomegaly and laboratory findings this clinical entity should be kept in mind.

Key words: hemophagocytic lymphohistiocytosis, necrotic arachnidism, systemic loxoscelism, violin spiders.

Loxoscelism is caused by the bites of Loxosceles genus spider, generally known as brown spiders or violin spiders. They have a worldwide distribution, predominantly found in the hot climate and tropical areas. Loxosceles recluse is the best known Loxosceles spider in the world, especially in the United States. $L$. rufescens is common around entire Europe and Mediterranean countries. In Turkey, most of the cases are caused by L. rufescens. ${ }^{1}$

The clinical condition caused by Loxosceles spider bite is called loxoscelism. In cutaneous loxoscelism, local skin reaction develops at the

\footnotetext{
Tuğba Erat

tugbacancan84@hotmail.com
}

Received 16th September 2019, revised 14th January 2020, accepted 27th January 2020

This study was presented at the 11th National Pediatric Infectious Diseases Congress, 4-8 April 2018, Antalya, Turkey. bite site and varies from mild and local to severe ulcerative necrosis with eschar formation. The ulcerative necrosis may develop due to the enzymes secreted by the spiders' venom, including hyaluronidase, esterase, alkaline phosphatase, and sphingomyelinase D. Severe systemic reactions such as fever, chills, nausea, arthralgia, myalgia, hemolysis, coagulopathy, and organ dysfunction rarely develop. These clinical manifestations are called systemic loxoscelism and is mostly encountered in children. ${ }^{2-4}$

Hemophagocytic lymphohistiocytosis (HLH) is a syndrome characterized by severe inflammation caused by pathologic immune activation and is nearly always fatal if left untreated. HLH is classified as primary and secondary. Primary HLH, an inherited form of hemophagocytic lymphohistiocytosis syndrome, is a heterogeneous autosomal recessive disorder and found to be more 
prevalent with parental consanguinity. Secondary HLH usually refers to patients who have no known underlying genetic cause of HLH. In secondary HLH, pathologic immune activation is often precipitated by an infection, toxins, rheumatologic disorder, or malignancy. The guidelines of HLH was published by Henter et al. ${ }^{5}$ in 2004 and diagnostic criteria of $\mathrm{HLH}$ include fever $>38.5^{\circ} \mathrm{C}$, splenomegaly, bicytopenia, hypertriglyceridemia and/or hypofibrinogenemia, and hemophagocytosis. In HLH-2004, the following three additional criteria were introduced; low/absent NK-cellactivity, hyperferritinemia, and high- soluble interleukin-2-receptor levels. Altogether five of these eight criteria must be fulfilled unless family history or molecular diagnosis is consistent with HLH. ${ }^{5,6}$ In Turkey, HLH associated with toxins of loxoscelism has not been reported. We reported a previously healthy five years old male patient who developed secondary HLH from a presumed brown spider bite. Informed consent was obtained from the parents.

\section{Case Report}

A previously healthy five years old boy living in the Zonguldak area of the Northern region of Turkey had a red spot, like an insect bite, just above the left eyebrow, which was noticed by his parents (Fig. 1). Three days after the red spot was seen, the erythema expanded, and edema occurred on the left eyebrow and eyelid. He was hospitalized at a local hospital's dermatology service on the second week (Fig. 2). Ampicillinsulbactam, amikacin, vancomycin, ceftriaxone, metronidazole, methylprednisolone, and pheniramine treatments were initiated. He received the treatment for five days; however, erythema and edema continued to expand. Originating from the first red spots localization, skin necrosis developed above-left eyebrow. $\mathrm{He}$ was referred to the city's university hospital after five days. Systemic penicillin, metronidazole, clindamycin, gentamicin, streptomycin, ciprofloxacin, fluconazole, methylprednisolone, pheniramine, ibuprofen, and local therapy, including moxifloxacin eye

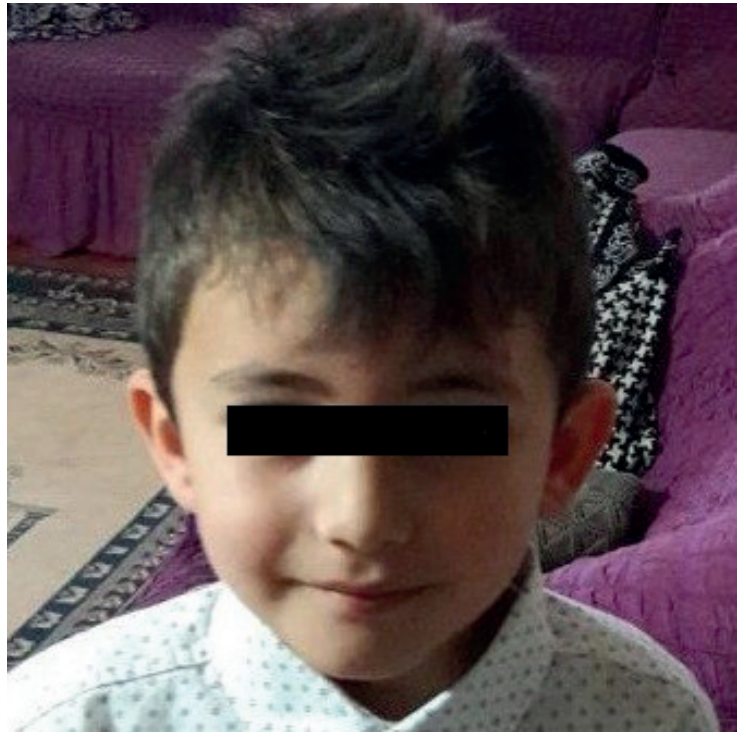

Fig. 1. Spider bite lesion above the left eyebrow (photo taken by the family).

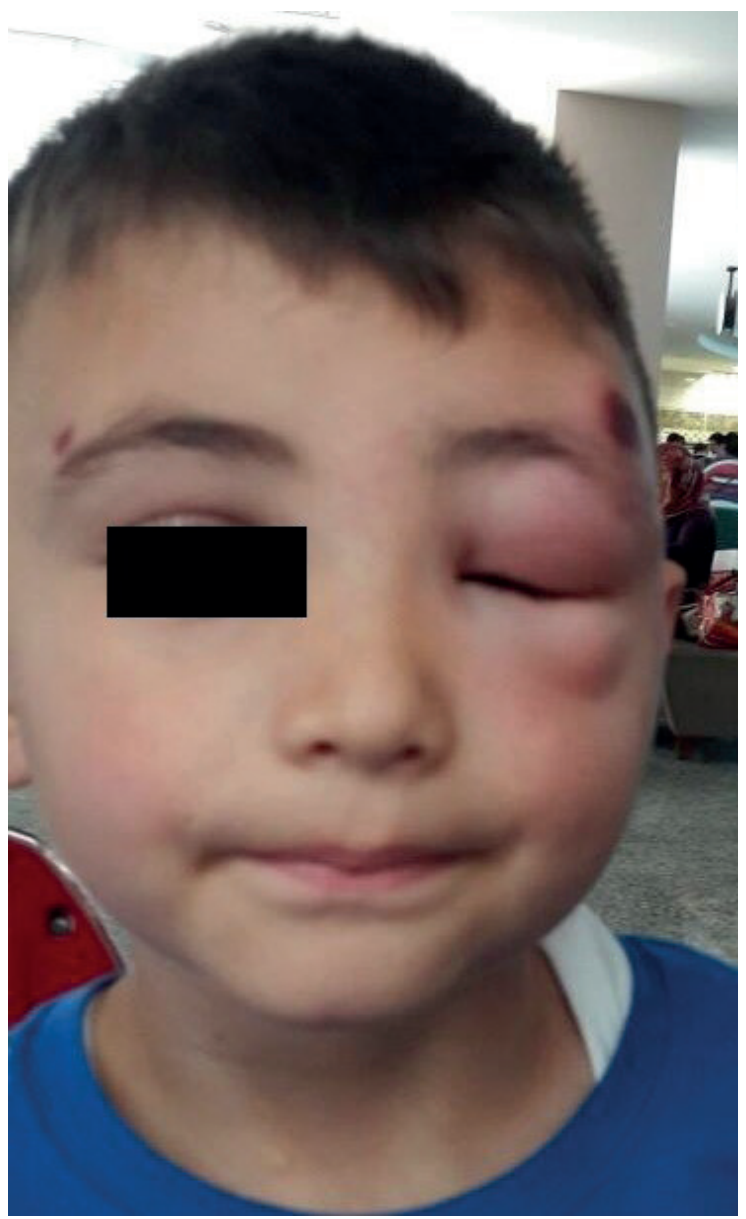

Fig. 2. Left eyebrow lesion (photo taken by the family before admission to regional hospital). 
drop, bacitracin, and neomycin pomade, were initiated. A biopsy was obtained from the necrotic area, and gram positive cocci and yeast cell presence was reported. Tests were negative for tuberculosis and tularemia. In spite of the treatment, erythema, edema and necrosis expanded, and fever developed. After fourteen days, the patient was referred to our hospital with a diagnosis of treatment-resistant preseptal cellulitis.

Upon admission, the patient had an acute onset of malaise, nausea, and fever. The patient's vital signs were normal, except for a body temperature of $38.5^{\circ} \mathrm{C}$. On clinical examination, the patient had bilateral severe eyelid edema that was more prominent on the left side, a superficial necrotic crust at above-left eyebrow (about $6 \mathrm{~cm}$ in diameter), erythema of bilateral eyelids and left side of the face and neck (Fig. 3). Ophthalmological examination revealed 0.7/0.7 visual acuity for both eyes, with normal anterior and fundus findings as well as regular motions with normal pupillary reflexes. Palpable noninflamed lymph nodes

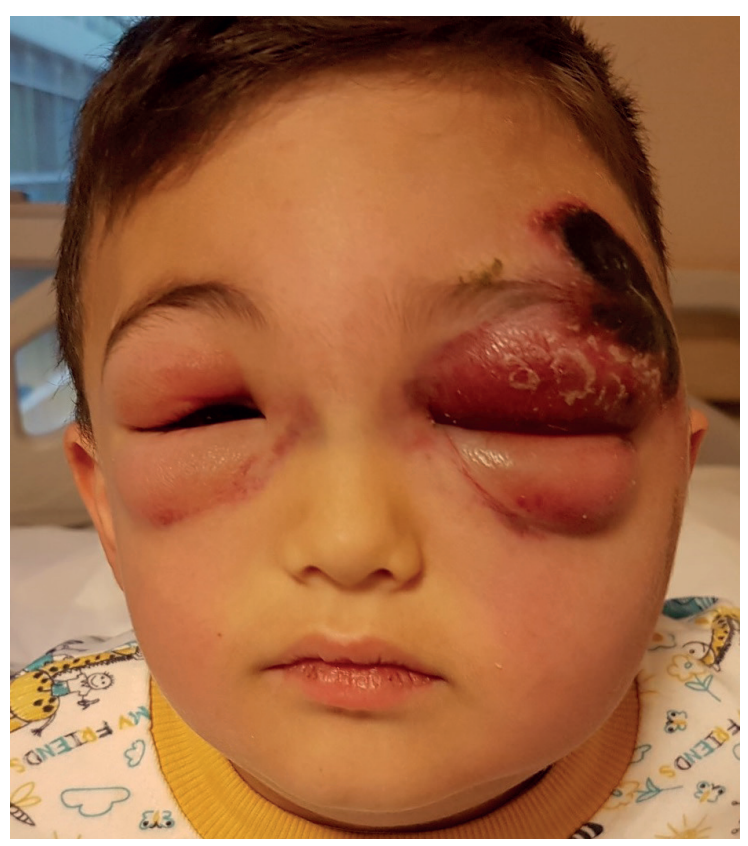

Fig. 3. Necrotic lesion on the left eyebrow and diffuse eyelid and facial edema (photo taken during our referral in our hospital). were present in left submandibular and cervical areas. Liver and spleen were two centimeters palpable under arcus costalis. Initial laboratory evaluation revealed high ALT and AST, and slightly low white-cell count and platelet count (Table I). Computer tomography scan revealed; periorbital, facial, and submental diffuse subcutaneous edema that was more prominent on the left side. The inflammation was considered as preseptal cellulitis (orbital cellulitis was excluded). The left parotid gland was also under the effect of inflammation. Left cervical, submandibular, and supraclavicular lymph nodes were palpable. Acute thrombosis was present at the left superficial temporal vein. When the medical history of the patient was revised in detail, the parents remembered that they found a little brown spider at home, and mentioned that the patient had a red spot like an insect bite approximately one centimeter above the left eyebrow. Based on the history and presenting symptoms, the etiology of his disease was consistent with a brown spider bite causing systemic loxoscelism.

The patient received a variety of antibiotics, including vancomycin, meropenem, and liposomal amphotericin B. On the 10th day, liposomal amphotericin B stopped because of resistant hypokalemia, and micafungin was initiated. The patient received $2 \mathrm{~g} / \mathrm{kg}$ IVIG treatment. Enoxaparin was started for acute venous thrombosis prophylaxis, and dapsone was initiated for possible loxoscelism. Local hyperbaric oxygen therapy (HBOT) was applied for necrotic areas. Our patient received 30 days of HBOT. The patient was consulted with the pediatric immunology department, and the immunologic tests were normal. Drug reaction and ecthyma gangrenosum were excluded.

After three days, the patient had a fever, hepatosplenomegaly, deepened pancytopenia, elevated triglyceride, elevated ferritin, and low fibrinogen levels (Table I). HLH was considered, and bone marrow biopsy was performed and the result was consistent with hemophagocytic syndrome (Fig. 4). Dexamethasone $10 \mathrm{mg} /$ $\mathrm{m}^{2}$ was intravenously initiated. Within the 
Table I. Laboratory data of the patient.

\begin{tabular}{|c|c|c|c|c|}
\hline Variable & $\begin{array}{c}\text { On } \\
\text { admission }\end{array}$ & $\begin{array}{l}\text { 8th day of } \\
\text { admission }\end{array}$ & $\begin{array}{l}\text { 30th day of } \\
\text { admission }\end{array}$ & $\begin{array}{c}\text { Reference } \\
\text { range* }\end{array}$ \\
\hline White-cell count (per $\mathrm{mm}^{3}$ ) & 4570 & 1600 & 9000 & $5000-13500$ \\
\hline Hemoglobin (g/dl) & 12.1 & 7.3 & 8.7 & $11.5-15$ \\
\hline Hematocrit (\%) & 34.3 & 21.3 & 26.8 & $34-45$ \\
\hline \multicolumn{5}{|l|}{ Differential count (\%) } \\
\hline Neutrophils & 55.6 & & & $35-65$ \\
\hline Lymphocytes & 37.7 & & & $30-55$ \\
\hline Monocytes & 4.5 & & & $2-9$ \\
\hline Platelet count (per mm3) & 106.000 & 76.000 & 324.000 & $150.000-450.000$ \\
\hline Erythrocyte sedimentation rate $(\mathrm{mm} / \mathrm{hr})$ & 8 & & & $0-20$ \\
\hline C-reactive protein (mg/L) & 0.1 & 0.1 & & $<5.0$ \\
\hline Sodium (mEq/L) & 137 & 135 & & $136-145$ \\
\hline Potassium (mEq/L) & 4.5 & 3.2 & & $3.5-5.1$ \\
\hline Calcium (mg/dl) & 8.2 & 8.5 & & $8.7-10.4$ \\
\hline Creatinine (mg/dl) & 0.27 & 0.32 & & $0.32-0.6$ \\
\hline Aspartate aminotransferase (U/L) & 163 & & & $<34$ \\
\hline Alanine aminotransferase (U/L) & 208 & & & $10-49$ \\
\hline Ferritin $(\mathrm{ng} / \mathrm{ml})$ & & 6856 & 32 & $22-322$ \\
\hline Triglyceride (mg/dl) & & 516 & 165 & $<150$ \\
\hline Fibrinogen $(\mathrm{g} / \mathrm{L})$ & & 1.42 & 1.66 & \\
\hline
\end{tabular}

*Reference values are affected by many variables. The ranges used at Ankara University Hospitals are adjusted for patient who are not pregnant and do not have medical conditions that could affect the results. And ranges are not age-adjusted. They may therefore not be appropriate for all patients.

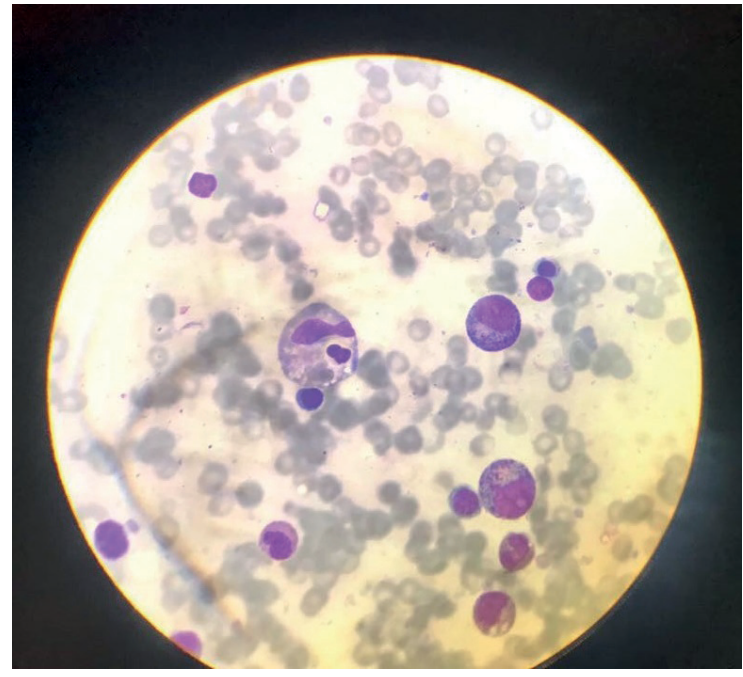

Fig. 4. A bone marrow aspirate demonstrated hemophagocytosis.

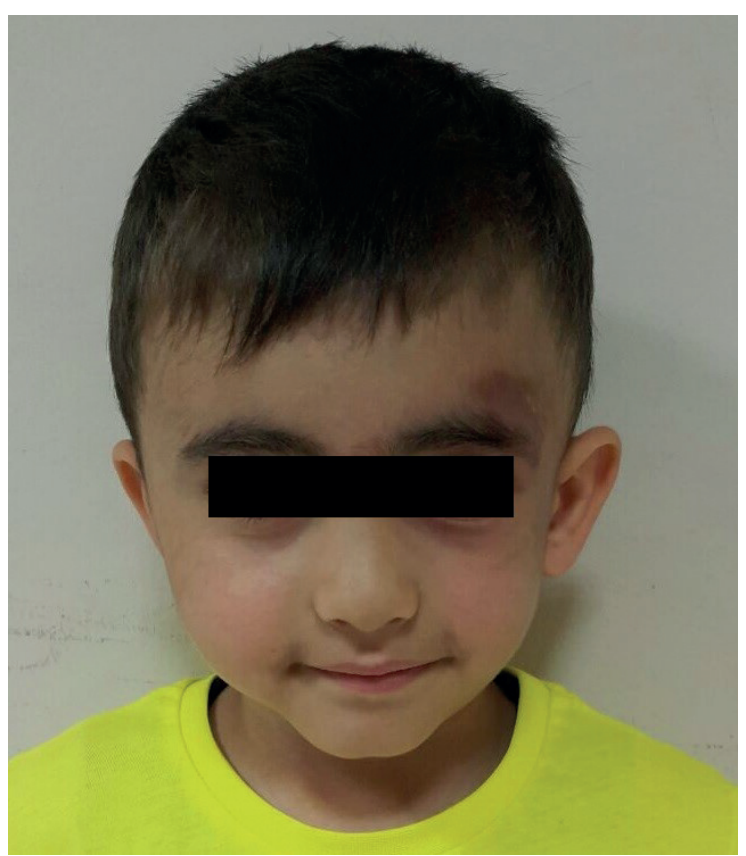

Fig. 5. Regression of necrotic lesion on the left eyebrow and facial edema (photo taken during follow-up). 
following 14 days, hemophagocytic syndrome findings gradually resolved. His facial lesions showed improvement for the first of two weeks, with a decrease in erythema and edema. Necrotic crust expanded through the left eyelid. The patient picked off the necrotic crust, and fresh tissue came into view. He received vancomycin for 14 days, meropenem for 28 days, liposomal amphotericin B for eight days, micafungin for six days. At follow-up admissions, his facial lesions improved (Fig. 5). Abdominal ultrasound and temporal artery doppler ultrasound were performed, and both reported regular findings.

\section{Discussion}

The diagnosis of a spider bite is typically based on patients' history and epidemiological findings, clinical signs and symptoms, and morphological appearance of the cutaneous lesion. The patient was referred to our hospital with the diagnosis of treatment-resistant preseptal cellulitis. However, on clinical examination, a local cutaneous reaction was observed with severe ulcerative necrosis and eschar formation at the bite site. Clinical signs, systemic symptoms, and appearance of the cutaneous lesion supported the diagnosis of loxoscelism. Similar cases with dermonecrosis were previously reported in the literature. ${ }^{7,10}$

The venom triggers a complex inflammatory response that causes an ischemic-reperfusion injury and enhances dermonecrosis. The pathophysiology of the ischemic reperfusion injury includes adherence of neutrophils to microvascular endothelium and subsequent basal membrane and interstitial tissue penetration. These neutrophils produce reactive oxygen metabolites that cause tissue cytotoxicity. Because of the microvascular injury, hyperbaric oxygen therapy (HBOT) should be considered. ${ }^{11,12}$ Hadanny et al. ${ }^{11}$ reported the effect of HBOT on non-healing wounds caused by brown spider bites. Our patient received 30 days of HBOT.
Presence of fever, pancytopenia, hepatosplenomegaly, hypertriglyceridemia, hyperferritinemia raised the concerns of HLH. Bone marrow biopsy was performed and lead us to the confirmation of HLH diagnosis. Hemophagocytic syndrome findings resolved with dexamethasone therapy. The patient had no underlying genetic disorder suggesting primary HLH. Age of the patient, absence of consanguinity between parents and family history of HLH, early recovery of findings only by steroid, and treatment of the underlying disease support the diagnosis of secondary HLH. To the best of our knowledge the case presented here is the first secondary $\mathrm{HLH}$ associated with loxoscelism in Turkey. The pathologic process affecting patients with $\mathrm{HLH}$ is the uncontrolled production of cytokines creating an abnormal accumulation and dysregulation of cytotoxic T cells, NK cells, and macrophages. Interferon-gamma, IL-6, IL-10, IL-12, and soluble IL-2 receptors are the key cytokines found in patients with HLH. 5,6,13,14 The underlying pathogenesis affecting patients with systemic loxoscelism is not fully understood, but the venom of loxosceles spider contains several enzymes. Sphingomyelinase D, a proinflammatory protein stimulating the activation of IL-6, IL-8, IL-10, is the main component of the venom. ${ }^{6,15}$ Therefore, the HLH clinic can also occur in systemic loxoscelism. Initial standard therapy for HLH includes dexamethasone and etoposide. In our patient, hemophagocytic syndrome resolved with dexamethasone.

In conclusion, the case presented here is the first case of secondary HLH associated with loxoscelism in Turkey. Clinicians must be aware of the possibility of HLH after systemic loxoscelism. Further investigation is needed to clarify the relationship between HLH and loxoscelism.

\section{REFERENCES}

1. Cesaretli Y, Ozkan O. A clinical and epidemiological study on spider bites in Turkey. Asian Pac J Trop Med 2011; 4: 159-162. 
2. Bajin MS, Arikan G, Parlak M, et al. Necrotic arachnidism of the eyelid due to Loxosceles rufescens spider bite. Cutan Ocul Toxicol 2011; 30: 302-305.

3. Taşkesen M, Akdeniz S, Taş T, Keklikçi U, Taş MA. A rare cause of severe periorbital edema and dermonecrotic ulcer of the eyelid in a child: brown recluse spider bite. Turk J Pediatr 2011; 53: 87-90.

4. Swanson DL, Vetter RS. Loxoscelism. Clin Dermatol 2006; 24: 213-221.

5. Henter JI, Horne A, Aricó M, et al. HLH-2004: Diagnostic and therapeutic guidelines for hemophagocytic lymphohistiocytosis. Pediatr Blood Cancer 2007; 48: 124-131.

6. Dandoy C, Grimley M. Secondary hemophagocytic lymphohistiocytosis (HLH) from a presumed brown recluse spider bite. J Clin Immunol 2014; 34: 544-547.

7. Kose A, Çete Y, Eken C, Kose B. Loxosceles ısırı ğına bağlı gelişen nekrotizan araknidizm: olgu sunumu ve literatürün gözden geçirilmesi. Türkiye Acil Tıp Dergisi 2006; 6: 181-185.

8. Yigit N, Bayram A, Ulasoglu D, Danısman T, Corak Ocal I, Sancak Z. Loxosceles spider bite in Turkey (Loxosceles rufescens, Sicariidae, Araneae). J Venom Anim Toxins Incl Trop Dis 2008; 14: 178-187.

9. Sams HH, Dunnick CA, Smith ML, King LE Jr. Necrotic arachnidism. J Am Acad Dermatol 2001; 44: 561-573.
10. da Silva PH, da Silveira RB, Appel MH, Mangili OC, Gremski W, Veiga SS. Brown spiders and loxoscelism. Toxicon 2004; 44: 693-709.

11. Hadanny A, Fishlev G, Bechor Y, Meir O, Efrati S. Nonhealing wounds caused by brown spider bites: application of hyperbaric oxygen therapy. Adv Skin Wound Care 2016; 29: 560-566.

12. Zamboni WA, Roth AC, Russell RC, Graham B, Suchy H, Kucan JO. Morphologic analysis of the microcirculation during reperfusion of ischemic skeletal muscle and the effect of hyperbaric oxygen. Plast Reconstr Surg 1993; 91: 1110-1123.

13. Osugi Y, Hara J, Tagawa S, et al. Cytokine production regulating Th1 and Th2 cytokines in hemophagocytic lymphohistiocytosis. Blood 1997; 89: 4100-4103.

14. Imashuku S. Advances in the management of hemophagocytic lymphohistiocytosis. Int J Hematol 2000; 72: 1-11.

15. Tambourgi DV, Petricevich VL, Magnoli FC, Assaf SL, JancarS, Dias Da Silva W. Endotoxemic-like shock induced by Loxosceles spider venoms: pathological changes and putative cytokine mediators. Toxicon 1998; 36: 391-403. 